\title{
Author Correction: Equation of state of iron under core conditions of large rocky exoplanets
}

Raymond F. Smith (D), Dayne E. Fratanduono, David G. Braun, Thomas S. Duffy, June K. Wicks, Peter M. Celliers, Suzanne J. Ali, Amalia Fernandez-Pañella, Richard G. Kraus, Damian C. Swift, Gilbert W. Collins and Jon H. Eggert

Correction to: Nature Astronomy https://doi.org/10.1038/s41550-018-0437-9, published online 16 April 2018.

In the version of this Letter originally published, in the Acknowledgements, the surname of M. Herrmann was misspelt as 'Hermann'. This has now been corrected.

Published online: 24 April 2018

https://doi.org/10.1038/s41550-018-0477-1 